\title{
The finite element analysis of L-shaped concrete columns confined by stirrups under axial repeated loads \\ Xiaowei Wang ${ }^{1, a}$, Shihua Wei $^{2}$ and Depeng Zhang ${ }^{3}$ \\ ${ }^{1,2,3}$ Civil Engineering and Transportation Institute, Hebei University of Technology, Tianjin \\ awangxw0424@163.com
}

\begin{abstract}
Keywords: axial repeated load, L-shaped column, finite element analysis, constrained mechanism Abstract. To study the confinement mechanism of L-shaped concrete columns confined by stirrups under axial repeated loads, based on the experiments the finite element analysis of five columns was carried out by ANSYS software. The results show that the calculation results of the peak load, peak displacement and skeleton curve are in good agreement with the test results, which proved that the model is reasonable and can be used to analyze the mechanical behavior of L-shaped concrete columns confined by stirrups under axial repeated loads. According to the calculation results of stress distribution of concrete section, the confinement mechanism of stirrups under axial repeated loads was studied. The effective constraint is the strongest within the stirrup plane, which can be divided into three parts: the effective constraint area, the weak constraint area and the unconstraint area. The weak constraint area is in the shape of an arch. And the weak constraint area between the adjacent stirrups is also an arch distribution, the weakest constraint section is the middle section, and the arch height decreases with the stirrup spacing decreasing.
\end{abstract}

\section{Introduction}

The L-shaped column is the specific shape of frame column which need to meet the required structural strength and stiffness. To improve the strength and ductility of L-shaped concrete column, the proper amount of stirrups should be arranged in the L-shaped column to restrict the lateral expansion deformation of the core concrete, so the core concrete is in the three-dimensional stress state. The mechanical behavior of L-shaped concrete columns confined by stirrups under axial loads was studied in the literature [1-2]. The relationship between strength, deformation, stress-strain curve and stirrup characteristic value of the core concrete were also studied. At present, many domestic and foreign references have studied the confined concrete theory of rectangular columns and circular column stirrups under axial load [3-6]. Because of the existence of the internal corners of L-shaped section, the confinement effect of the core concrete must be different from the above columns. In recent years, the references mainly studied the bearing capacity and hysteretic behavior of L-shaped column [7-9]. The study of L-shaped concrete columns confined by stirrups under axial repeated load is not available. Therefore, based on the axial repeated load experiment, the finite element analysis of L-shaped columns confined by stirrups was carried out, it was analyzed the stress distribution of the core concrete to study the confinement mechanism of the stirrups, which can provide reference for the mechanical behavior analysis of L-shaped concrete columns confined by stirrups under axial repeated loads.

\section{Specimen Design}

Considering the factors such as the stirrup form, the stirrup spacing and the stirrup characteristic value, five specimens were designed. For the convenience of loading, the both ends section of the specimens are
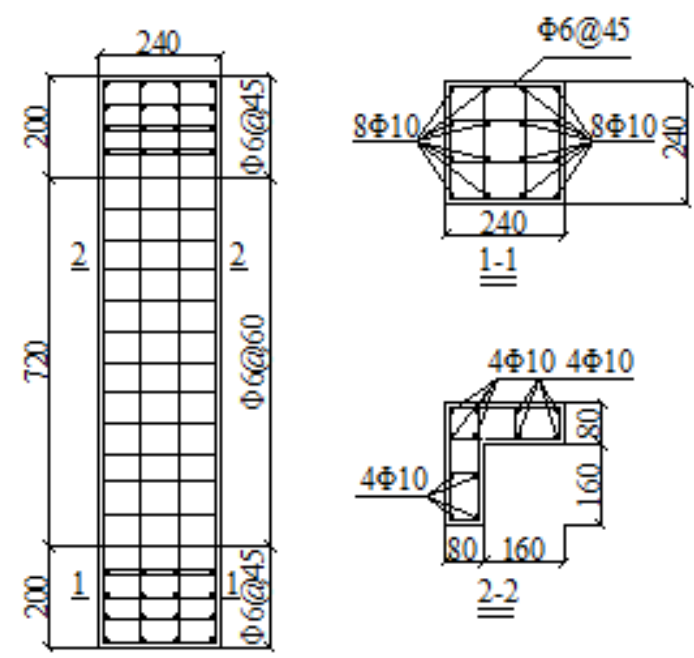

Fig.1 Designed size and reinforcement of specimens 
rectangular, and the middle $720 \mathrm{~mm}$ section is $\mathrm{L}$ shape. As shown in Figure 1, the longitudinal reinforcement of specimen was $12 \phi 10$, the thickness of the protective layer was $10 \mathrm{~mm}$, the stirrup was $\phi 6$. Measured limb height was $270 \mathrm{~mm}$, limb thickness was $110 \mathrm{~mm}$, stirrup spacing $s$, volume stirrups rate $\rho_{v}$ were shown in Table 1 . The design strength of concrete was C30, and the measured compressive strength $f_{c}$ and peak strain $\varepsilon_{0}$ of concrete were shown in Table 1 . Through the tensile strength test of steel bars, the yield strength of longitudinal reinforcement was $380 \mathrm{MPa}$, the elastic modulus was $2.16 \times 10^{5} \mathrm{MPa}$, the yield strength of stirrup was $460 \mathrm{MPa}$, and the elastic modulus was $2.10 \times 10^{5} \mathrm{MPa}$. The calculated reinforcement characteristic values based on the measured results were also shown in Table $1\left(\lambda_{v}=\rho_{v} \times f_{y v} / f_{c}, f_{y v}\right.$ is yield strength of stirrups). 5000kN electro-hydraulic servo pressure machine was used to apply axial repeated load. The loading scheme was the equal strain increment full cycle, and the strain increment was $1 \times 10^{-3}$.

Tab.1 Measured parameters and test results

\begin{tabular}{ccccccccccccc}
\hline Number & $\mathrm{s} / \mathrm{mm}$ & $\rho_{v} / \%$ & $f_{c} / \mathrm{MPa}$ & $\varepsilon_{0} / 10^{-6}$ & $\lambda_{v}$ & $\mathrm{P}_{\mathrm{u}} / \mathrm{kN}$ & $\Delta_{u} / \mathrm{mm}$ & $\mathrm{P}_{\mathrm{u}}{ }^{\prime} / \mathrm{kN}$ & $\Delta \mathrm{u}^{\prime} / \mathrm{mm}$ & $\mathrm{u}_{\mathrm{p}} / \%$ & $\mathrm{u}_{\mathrm{p}}{ }^{\prime} / \%$ \\
\hline L-1 & 180 & 0.549 & 36.8 & 7716 & 0.0785 & 1595 & 5.78 & 1438 & 5.43 & 9.8 & 6.1 \\
L-2 & 120 & 0.824 & 37.1 & 8156 & 0.1080 & 1699 & 6.19 & 1569 & 5.52 & 7.7 & 10.8 \\
L-3 & 100 & 0.990 & 30.8 & 7500 & 0.1462 & 1416 & 6.47 & 1370 & 5.97 & 3.3 & 7.7 \\
L-4 & 80 & 1.236 & 31.1 & 7986 & 0.1931 & 1512 & 7.09 & 1424 & 6.15 & 5.8 & 13.3 \\
L-5 & 60 & 1.649 & 36.5 & 7930 & 0.2295 & 1750 & 7.70 & 1643 & 6.59 & 6.1 & 14.4 \\
\hline
\end{tabular}

\section{Finite Element Model}

In the analysis model, the concrete element used Solid 65, and the constitutive relation was adopted by the German scholar Rusch's concrete uniaxial compressive stress-strain constitutive curve model. The ascending section of the model is a parabola, and the descending section is a horizontal line. The Von Mises yield criterion, multi-linear isotropic hardening plasticity (MISO) and Willam-Warnke five parameter failure model were used. Stirrup element used Link 8, the ideal elastoplastic stress-strain relationship model and the bilinear isotropic hardening plasticity (BISO) were used. By using the separate modeling, the transverse deformation of the core concrete element was restricted by the stirrup element, so that the core concrete was in the three-dimensional stress state. The finite element model of the L-shaped concrete columns was

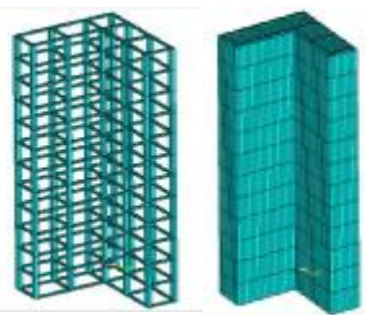

Fig.2 Finite element model of L-shaped columns confined by stirrups shown in Figure 2.

All the nodes at the bottom of the column were constrained by all degrees of freedom so that the L-shaped column became a cantilever. The displacement load was applied on the top of the column, which was divided into two steps of loading and unloading. According to the test requirements, each load step in the loading process used an equal displacement increase, each loading step was divided into 10 sub-steps. In the unloading process, reduces the displacement according to the actual situation until the force to 0 . Each unloading step was divided into 10 sub-steps, and then to the next load. To avoid convergence and save computation time, the automatic time step can be activated so as to adjust the time step as needed to achieve a good balance between the accuracy and the computational cost.

\section{Results Analysis}

The test results $P_{u}$, calculation results $P_{u}^{\prime}$ of the peak load and the relative error $u_{p}$ of them were shown in Table 1.The test results $\Delta_{\mathrm{u}}$, calculation results $\Delta_{\mathrm{u}}{ }^{\prime}$ of the peak displacement and the relative error $\mathrm{u}_{\Delta}$ of them were also shown in Table 1. It can be seen that the calculation results of the peak load and the peak displacement agree well with the test results, and the relative error between the calculation 
results and the test results are within $15 \%$. Therefore, the analysis model used in this paper can analyze the peak load and peak displacement of L-shaped concrete columns confined by stirrups under axial repeated load.

The calculation results of the skeleton curves were compared with the test results as shown in Figure 3. It can be seen that the calculation results are in good agreement with the test results.

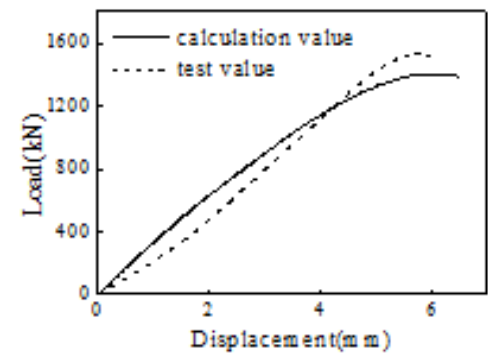

(a)L-1

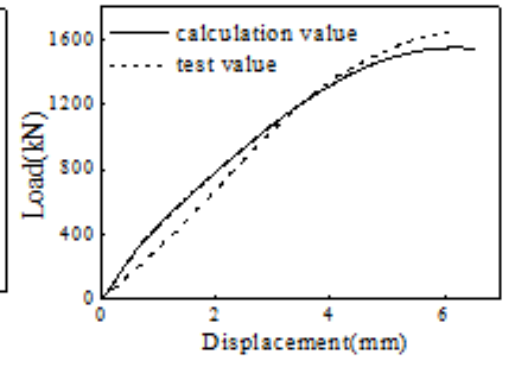

(b)L-2

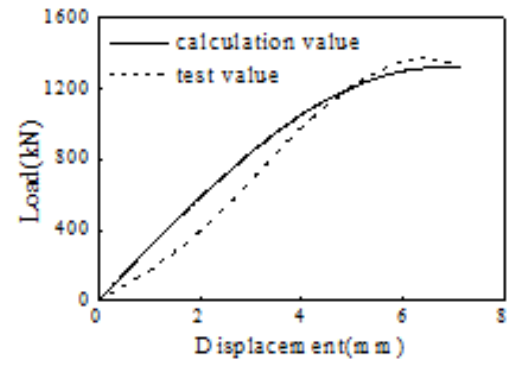

(c)L-3

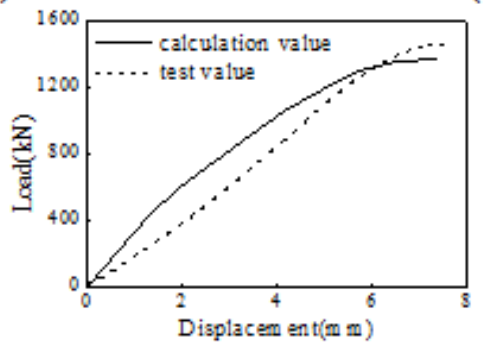

(d) $\mathrm{L}-4$

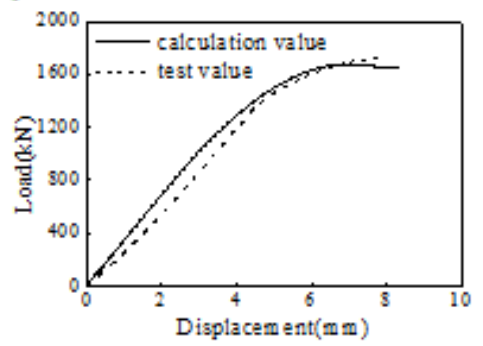

(e) L-5

Fig.3 Comparison of load-displacement skeleton curves of specimens

At the peak load, the concrete stress distributions within the stirrup plane were shown in Figure 4. It can be seen that the bearing capacity of the concrete protection layer is poor with no stirrup constrain, so it can be called an unconstrained area. The concrete stress of the stirrup straight section is relatively low because of the horizontal expansion of the core concrete to make the stirrup produce horizontal bending, so the bending rigidity of the stirrup is low and the reaction force acting on the core concrete is small. Therefore, the weak constrained area of the arch inside of the stirrups is formed. The middle section outside arch and the section extension to the corner have relatively high bearing capacity, so they can be called the effective constrained area. 


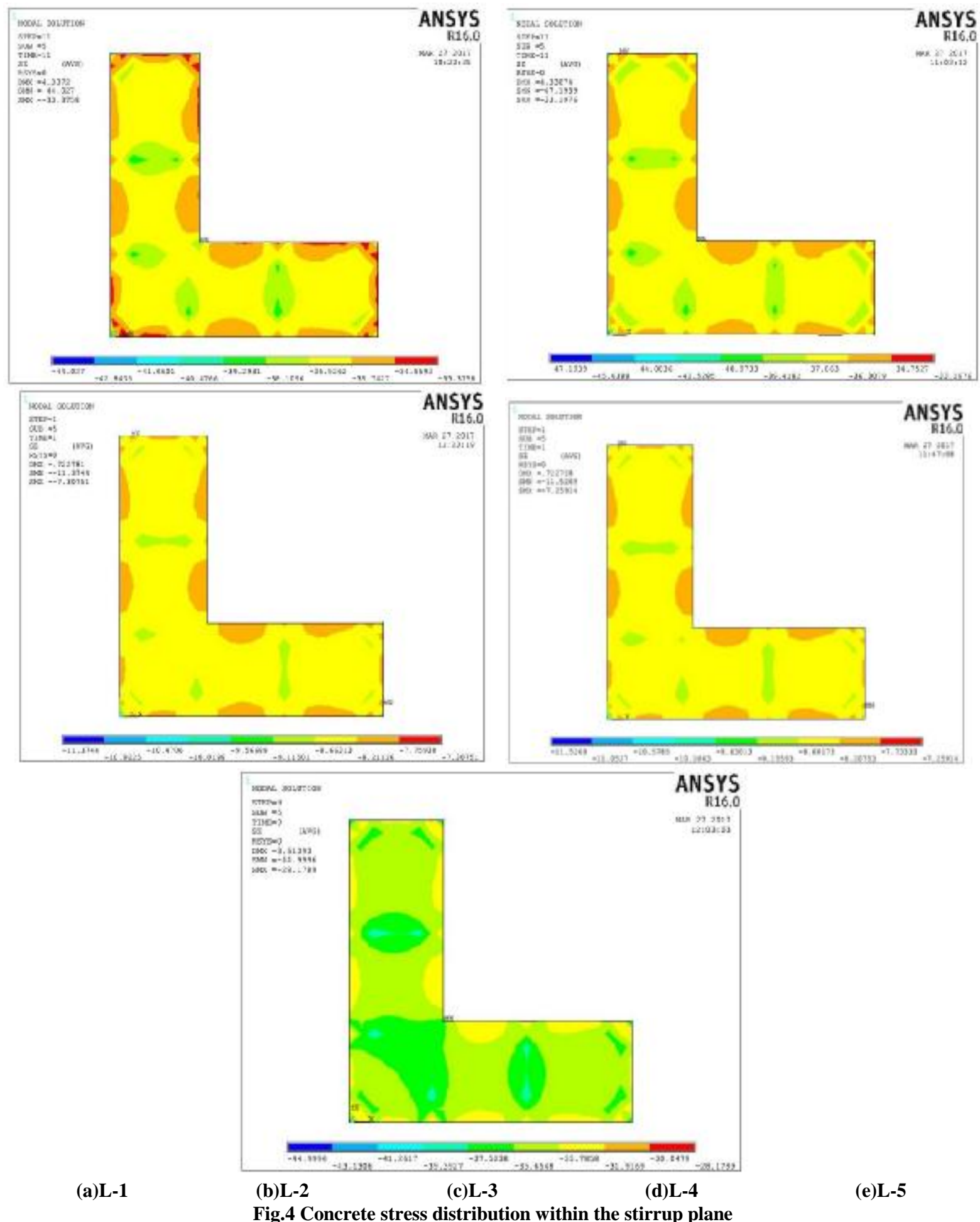

At the peak load, the concrete stress distribution of longitudinal section of L-shaped columns were shown in Figure 5, it can be seen that the concrete stress is higher within the stirrup plane, the constrained effect is the strongest. The constrained effect between the two adjacent stirrups is relatively weak, and the weakest constrained section is the middle. The confinement mechanism between the stirrups is the same as that of the stirrup plane. The area can be divided into the effective constrained area, the weak constrained area and the unconstrained area along the longitudinal direction. The weak constrained area shape is also an arch. According to the analysis of the concrete stress distributions of columns,
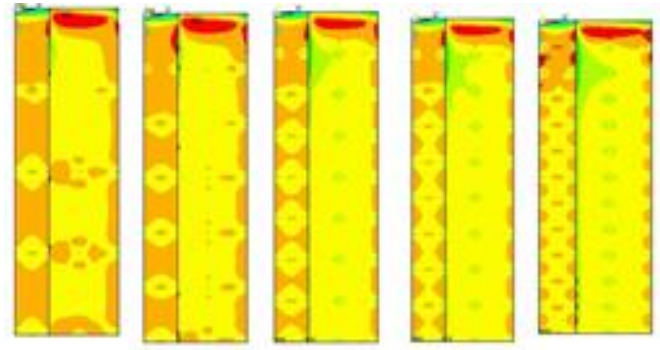

$\begin{array}{lllll}\text { (a) } \mathrm{L}-1 & \text { (b) } \mathrm{L}-2 & \text { (c) } \mathrm{L}-3 & \text { (d) } \mathrm{L}-4 & \text { (e) L-5 }\end{array}$

Fig.5 Concrete longitudinal stress distribution 
the arch height decreases, the arch height is about 1/7-1/12 of the stirrup spacing.

The arch height is mainly related to the stirrup characteristic value. With the increase of the stirrup characteristic value, the arch height and the weak constrained area decrease, the constrained effect on the core concrete increases, and the bearing capacity of the concrete increases.

\section{Conclusions}

In this paper, through the finite element analysis of L-shaped concrete columns confined by stirrups under axial repeated loads, the main conclusions are as follows:

1.The calculation results of the peak load, peak displacement and skeleton curve are in good agreement with the test results, which proved that the analysis model is reasonable and can be used to analyze the mechanical behavior of L-shaped concrete columns confined by stirrups under axial repeated loads.

2.According to the calculation results of the concrete stress distribution, the confinement mechanism of stirrups under axial repeated loads was studied. The effective constraint is the strongest within the stirrup plane, which can be divided into three parts: the effective constraint area, the weak constraint area and the unconstraint area. The weak constraint area is in the shape of an arch. And the weak constraint area between the adjacent stirrups is also an arch distribution, the weakest constraint section is the middle section, and the arch height decreases with the stirrup spacing decreasing.

\section{Acknowledgements}

This work was financially supported by the Hebei Natural Science Foundation (E2014202178).

\section{References}

[1] Wang Xiaowei. Experimental and theoretical research on performance of axially specially shaped columns confined by stirrups[D]. Tianjin University, 2009.

[2] Wang Tiecheng, Wang Xiaowei. Performance analysis of axially loaded L-shaped columns confined by stirrups[J]. Journal of Tianjin University, 2009, 42(9):770-776.

[3] Park.R,Kent D.C and Sampson R.A. Reinforced concrete member with cyclic loading.[J] ASCE. Journal of Structural Engineering, 1972, 98(7):1341-1360.

[4] R.Park,M.J.N.Priestley,W.D.Gill, Ductility of square-confined concrete columns[J], Journal of the Structural Division,ASCE,1982, 108(ST4):929-951.

[5] Zhang Xiuqin, Guo Zhenhai, Wang Chuanzhi. Stress strain curve equation of concrete under cyclic loading[J]. Industrial Construction, 1985, 12:16-20.

[6] Yuan Jingen. Ductility and hysteretic behavior of reinforced concrete bending members[R]. Symposium on theory and application of concrete strength and strength of Chinese Architectural Society, 1987, 10.

[7] Chen Zongping, $\mathrm{Xu}$ Jinjun, Zhan Donghui. Experimental study on hysteretic behavior of L-shaped SRC column-concrete beam joints[J]. China Civil Engineering Journal, 2016,49(9):30-40.

[8] Liu Zuqiang, Xue Jianyang, Zhao Hongtie. Analysis on the hysteretic behavior of steel reinforced concrete frame with special-shaped columns[J]. Engineering Mechanics, 2016, 33(7):73-82

[9] Xu Jinjun, Chen Zongping, Xu Yuliang. Comparative analysis of hysteretic behavior of special-shaped columns of $\mathrm{L}, \mathrm{T}$ and cross section steel reinforced concrete[J]. Journal of Experimental Mechanics, 2015, 30(2):221-230. 